\title{
CARACTERIZACIÓN DE LA SITUACIÓN IDIOMÁTICA DE LOS PUEBLOS INDÍGENAS DE COSTA RICA Y SU INFLUENCIA EN SU EDUCACIÓN
}

\author{
Ana Cecilia Vásquez Carvajal ${ }^{1}$ \\ Directora de la Escuela Ujarrás, en la Zona Sur de Costa Rica \\ Costa Rica
}

Recibido 12 de julio 2007 • Aprobado 15 de octubre 2007

\begin{abstract}
Resumen: Este ensayo muestra la realidad de los pueblos indígenas costarricenses en cuanto al dominio y promoción de su lengua original y la forma en que esta se toma en cuenta en los planes de estudio que se imparten en las escuelas de estas comunidades. Se afirma que el proceso educativo se desarrolla ajeno a la realidad idiomática y cultural de estos pueblos, y aun cuando se han realizado esfuerzos ministeriales, tienen debilidades que impiden avances significativos. Como resultado de estas deficiencias se genera un debilitamiento cultural que puede culminar con la pérdida de las lenguas nativas.
\end{abstract}

Palabras clave: Educación indígena, lenguas autóctonas, cultura.

\section{A}

bstract: This essay shows the reality of Costa Rican indigenous groups in terms of the mastery and promotion of their original tongue and the way this has been taken into account in the design of the curricula of their schools. In general, it is discussed that the educational process is developed disengaged of the idiomatic and cultural reality of these groups, even tough government efforts have been made in this direction. As a result of this educational deficiency, a cultural decline is generated that might end up with the loss of native languages.

Key words: Indigenous education, autochthonous languages, culture.

Si se analizan los orígenes de la educación indígena en Costa Rica, y específicamente, la promoción y enseñanza de la cultura e idiomas autóctonos hasta el año 1994, con dificultad, podría mencionarse la existencia de planes o programas estructurados que tuvieran el objetivo de desarrollar una educación, pedagógicamente sustentada, dirigida a fomentar, promover y fortalecer los valores

\footnotetext{
Graduada de la primera promoción de la Maestría en Educación Rural Centroamericana. Además, es Licenciada en Educación con énfasis en Educación Rural y Bachiller en Ciencias de la Educación con concentración en Educación Indígena. Directora de la Escuela Ujarrás, en la Zona Sur de Costa Rica, desde hace más de 10 años. Tiene experiencia en Educación de Adultos y Educación Indígena. Colaboradora y tutora de ferias científicas en niveles institucional, circuital, regional y nacional. Autora de calendarios de costumbres y tradiciones Cabécar, años 2004 y 2007-2008. Actualmente, labora como docente de educación especial itinerante en la Escuela San Vicente, ubicada a tres kilómetros de la Escuela de Ujarrás. Correo electrónico: famave2002@costarricense.cr
} 
y los enfoques culturales; y, mucho menos, las formas idiomáticas de la comunicación usadas por los pueblos originales costarricenses, en un marco de respeto, equidad y armonía intercultural.

Los registros ponen de manifiesto la realización de algunas acciones aisladas, que intentan acercarse a los fines mencionados, aunque en el fondo, denotan todo lo contrario; son iniciativas de adoctrinamiento religioso, jornadas de alfabetización en castellano para la asimilación, así como cartillas o textos para la lectoescritura en alguno de los idiomas indígenas más difundidos, tales como el bribri o el cabécar, pero que, en definitiva, no han logrado evitar y ni siquiera detener la creciente tendencia erosiva que sufren las culturas e idiomas indígenas nacionales.

En 1994 se formaliza la creación del Departamento de Educación Indígena (DEI) del Ministerio de Educación Pública (MEP), en congruencia con la necesidad de implementar programas para la promoción, la enseñanza y el fomento de las culturas y las lenguas indígenas de Costa Rica, mediante la educación formal. Sin embargo, no es sino hasta 1996 cuando realmente se generan tres programas específicos, uno de ellos dirigido a la promoción y la enseñanza de las lenguas indígenas, entre las cuales, aparece el cabécar, sobre todo por ser, existir y pervivir en ocho de los 24 territorios indígenas legalmente constituidos, y por ser idioma materno (L1) de la segunda población indígena más numerosa del país (más de 9000 personas hablantes), número superado únicamente por los bribris. Esto hace que el cabécar sea una lengua muy difundida, en relación con las otras cinco.

Uno de estos ocho territorios es Ujarrás, en Buenos Aires, provincia de Puntarenas, donde los cabécares coexisten con otros pueblos: dos comunidades bribris (Salitre y Cabagra), dos bruncas, también conocidos como borucas (Boruca y Rey Curré) y con el pueblo indígena térraba o téribe, que lucha, valientemente, contra la extinción.

Al inicio, y por desconocimiento, así como por lo novedoso que resultaba el tema indígena en el ámbito nacional, se lanza una iniciativa para rescatar, fomentar y difundir las culturas e idiomas autóctonos nacionales. Esta iniciativa tuvo un sentido genérico y generalizado, ya que una de las insuficiencias y común denominador para las ocho culturas y los seis idiomas, era la falta de información de todo tipo, a saber: demográfica, sociocultural, lingüística, etnográfica, socioeconómica, ambiental y productiva de los pueblos indígenas.

Surgieron posturas de fondo que aún permanecen en gran parte de la sociedad costarricense y que, de alguna forma, propician manifestaciones que van desde las más sutiles y románticas, hasta algunas grotescas y alevosas, precisamente porque, a través de los años, no se ha tratado el tema indígena con la objetividad y el respeto merecido, ni, mucho menos, se ha tratado la enseñanza desde la evolución interétnica e intercultural que, a lo largo de los siglos, se ha dado en la estructura sociocultural y política de esta sociedad.

En materia sociocultural e idiomática indígenas, y para estructurar procesos debidamente fundamentados y coherentes en esas materias, se puede decir que, entre las principales dificultades encontradas para desarrollar las iniciativas, en el año 94 así como para implementar planes de estudio coherentes con la realidad sociocultural y lingüística de cada uno de los pueblos indígenas nacionales, estaban:

1. La falta de sistematización, la fundamentación científico-técnica y las normativas lingüísticas para cada una de las seis lenguas indígenas nacionales aún existentes.

2. La ausencia de estrategias, planes, programas o modelos pedagógicos estructurados que orienten la enseñanza y el fomento de cada una de las lenguas indígenas nacionales, de acuerdo con la condición, el estadio de desarrollo y la evolución de cada una de ellas. 
3. La ausencia de personas hablantes, con dominio y propiedad de lectoescritura cabécar, y con formación pedagógica, que pudieran inducir e impulsar la enseñanza de la lengua autóctona local.

4. La inexistencia de material didáctico, textos y cartillas contextualizadas, acordes con las culturas indígenas locales, que favorecieran la alfabetización, la formación y la educación de los niños indígenas en el marco de su cultura y lengua naturales.

La información que se ha logrado recabar a lo largo de esta experiencia educativa en y con comunidades indígenas, que data desde 1989, refuerza la necesidad de desarrollar planes y talleres tendientes al fomento y fortalecimiento de las culturas indígenas nacionales.

En términos comparativos, la comunidad cabécar de Ujarrás tiene ligeramente mejores condiciones que las otras comunidades indígenas de la región, en cuanto a cercanía y accesibilidad del centro de desarrollo urbano más próximo; aunque también presenta una problemática mayor en su condición sociocultural, debido a estas relativas ventajas. Esta comunidad, ubicada a 30 minutos de Buenos Aires, con un camino más o menos transitable durante todas las épocas del año, y con una institución educativa con 77 años de existencia, presentaba, a inicios de los años 90, problemas graves en cuanto a la sobreedad de niños, niñas y jóvenes, la ausencia de servicios de educación preescolar, bajos niveles de aprestamiento y desarrollo de habilidades y destrezas socioafectivas en sus estudiantes.

Por otro lado, en la parte cognitiva, tienen dificultades por el poco conocimiento de su identidad y baja autoestima comunal, así como por el escaso fomento y reconocimiento de sus valores culturales. No tienen claro cuáles son sus indicadores socioculturales básicos, y cuáles elementos de la cultura cabécar es necesario desarrollar.

En un primer diagnóstico realizado sobre la comunidad cabécar (Costa Rica, Ministerio de Educación Pública [MEP]. Departamento de Educación Indígena [DEI], 1995), se detectaron aspectos negativos que perjudican la percepción de sí mismos, de la familia y de su comunidad. Entre ellos se encuentran los siguientes:

- $\quad$ Problemas de alcoholismo desde edades muy tempranas, propiciado por las ventas de chicha establecidas por no indígenas.

- $\quad$ Desempleo.

- $\quad$ Baja productividad en las tierras, tanto por la pérdida de éstas, como por la falta de recursos financieros para la inversión.

- $\quad$ Ausencia de iniciativas propias para el desarrollo y el autosustento.

- Embarazo juvenil e infantil, algunas veces por desconocimiento y otras por irresponsabilidad, tanto de jóvenes indígenas como no indígenas,

- Crecimiento y agudización de la falta de opciones para la superación por medio de la educación formal.

En este último punto, debe resaltarse el hecho de que en la comunidad sólo existía el servicio de educación primaria, por lo que la continuación de estudios secundarios debía hacerse en el Colegio Técnico Profesional (CTP) de Buenos Aires, opción que sólo unos pocos niños escogían. Es importante mencionar que esta opción era casi exclusivamente para varones, pues ninguna mujer llegó a intentarlo. Aparte de esto, unos pocos optaban por estudiar en el Colegio Nocturno de Buenos Aires, para lo cual tenían que caminar una distancia considerable, al final del día, cuando 
generalmente llueve, y regresar, a altas horas de la noche, ya que no existe un servicio de transporte adecuado ni con un horario permanente.

El interés y la disposición de los padres y las madres de familia para enviar a sus hijos e hijas a la escuela oficial chocaban, precisamente, con el interés por el fomento y el fortalecimiento de la cultura cabécar local. Al parecer, la escuela tiene el objetivo de sacar a los niños y a las niñas del "atraso" que les causa el hecho de ser indígenas. Los padres y las madres de familia tienen aún muy claro en sus mentes que uno de los requisitos, el cual se anunciaba públicamente en la pulpería de la comunidad, era que para ingresar en la escuela primaria era necesario hablar español. Por ello, muchos padres y jóvenes eran y aún son analfabetas en el español, aunque son hablantes y conocedores de su cultura e idioma.

Un aspecto importante y que no ha sido tomado en cuenta en el Programa para la enseñanza de lenguas indígenas del DEI-MEP, es el hecho de que el ámbito de desarrollo que presentan tanto las culturas como las lenguas indígenas costarricenses es muy disímil y heterogéneo (Santa Cruz y Van der Lat, 2007). Lo mismo ocurre, específicamente, con las lenguas autóctonas, según el calificado y objetivo análisis que hace Constenla (1994) en una síntesis de varios estudios desarrollados al respecto.

En gran medida, las situaciones sociocultural y lingüística tienen una estrecha relación, pues ubican a la lengua y a la cultura cabécar en un nivel de relativa posibilidad de sobrevivencia, o de potencial fortaleza para sobrevivir y superar la extinción. Así lo reflejan documentos e indicadores de los estudios de Santa Cruz y Van der Lat y de Constenla.

Los cinco grupos indígenas nacionales restantes están por debajo de la línea de sobrevivencia, en una condición difícil de revertir, o sea, están en vías de extinción. Por un lado, está el caso de las culturas y lenguas maleku, térraba y boruca, todos ellos con poca población hablante (indicador demográfico) y con un creciente proceso de erosión de valores y fundamentos filosófico-culturales, lo que, consecuentemente, demanda otro tipo, de atención sociopedagógica para el rescate y la promoción de sus culturas y de sus lenguas autóctonas.

Por otro lado, está el caso de los pueblos y culturas chorotega y huetar, ambos en virtual extinción, pues todos los indicadores y expresiones externas marcan, en el peor de los casos, una asimilación y una semejanza con las culturas rurales y campesinas de sus respectivas regiones: Matambú y Nicoya en Guanacaste, y Quitirrisí y Zapatón en Puriscal, San José. No es casual, por cierto, que éstas sean dos de las subregiones rurales más deprimidas en todo sentido, en el territorio nacional.

Esta caracterización del estado sociocultural e idiomático de los pueblos indígenas de Costa Rica, sirve para llamar la atención sobre el hecho de que el abordaje pedagógico y educativo no puede ser estandarizado, ni homogenizado, como hasta ahora lo ha venido haciendo el MEP, y, particularmente, el DEI, con los tres programas existentes. A cada estado de situación y nivel de fortaleza cultural y lingüística, ha de corresponder un tratamiento y una estrategia pedagógica coherente y particular.

Si se analizan con cuidado los planteamientos que desde hace once años viene haciendo el DEI-MEP, y específicamente el Programa para la enseñanza de la cultura y las lenguas indígenas nacionales, en cuanto a la conformación y formación del personal docente y la elaboración de planes de estudio, se puede determinar que no existe ni se aplica diferenciación para cada cultura, lengua y pueblo en particular, pese a que diversos estudios son claros respecto de esta necesidad.

El Programa de lengua cabécar carece de una visión y de lineamientos estratégicos en cuanto al qué hacer y para qué hacerlo, en su implementación curricular. Cabe señalar que no es lo mismo una estrategia pedagógica para rescatar, rehabilitar o promover las lenguas térraba, boruca o maleku, 
de acuerdo con su estado e indicadores, que desarrollar una estrategia pedagógica para la difusión, el fortalecimiento, la promoción y la proyección de las lenguas cabécar, bribri o gnöbe, las cuales presentan otra situación y una condición, relativamente, más favorable en vitalidad y fortaleza.

En la comunidad de Ujarrás, las poblaciones infantiles escolarizadas presentan situaciones lingüística y cultural muy conflictivas y particulares. Muchos de los niños y las niñas nacen y crecen en el seno del hogar rodeados de su cultura y de la protección materna, lo que asegura la asimilación de los valores y los elementos culturales más importantes; al igual que la crianza, la alimentación, las relaciones interpersonales y la lengua. Por esto, podría afirmarse que la gran mayoría de estos grupos hablan y dominan su lengua original. En estos casos, el hecho de ir a una escuela en la que el planteamiento educativo no se diferencie del resto de las escuelas del país, constituye un factor de agresión transculturizante.

En la institución educativa de Ujarrás, los niños y las niñas cabécares pueden ubicarse en alguna de las siguientes tres situaciones, respecto al uso y empoderamiento de su cultura, pero, ante todo, en el uso de su lengua, con respecto al español: 1. hay quienes lo hablan, lo que los hace niños y niñas bilingües; 2 . hay quienes lo hablan pero se avergüenzan y lo ocultan, y 3 . hay quienes ya no lo hablan, por desarraigo o por una falsa protección que quisieron darles sus padres (para que sus hijos e hijas no sufrieran la humillación y las burlas que se asocian con el ser y la cultura indígenas). Estas mismas situaciones se reflejan con las otras lenguas indígenas del territorio nacional.

Como la educación formal oficial se imparte en español, que sigue siendo el idioma oficial, al niño indígena se le sumerge en un conflicto pedagógico, al tener que aprender algo extraño, ajeno a su cultura (porque responde a la cultura occidental), y peor aún, un idioma también extraño y ajeno, con antecedentes de agresión e imposición. Es por ello que, en gran medida, muchos docentes, inconscientes de esta realidad, manifiestan que los(as) infantes indígenas son tímidos(as), porque no participan en clase; sin percatarse que para muchos de ellos el idioma español es aún desconocido y ajeno a sus habilidades y dominios cognitivos. Poco o ningún aporte pueden hacer al proceso, en su cultura y sus valores, porque en la escuela, además de haber sido menospreciados, lo que se fomenta y practica es contrario a sus formas de vida tradicionales, por no decir transculturizante.

En cuanto a los(as) docentes, es importante mencionar que a pesar de las acciones que se han implementado para su sensibilización, formación y seguimiento, y a pesar del reconocimiento y la oficialización de los programas para desarrollar procesos de educación indígena bilingüe, persisten en ellos, actitudes racistas (algunas sutiles y otras muy evidentes), discriminatorias y estigmatizantes, con respecto a las poblaciones indígenas, lo cual es más peligroso y dañino cuando de niñez y de adolescencia se trata, por el impacto y las secuelas que se dejan en estas edades.

A pesar de que se han cumplido trece años de haberse implementado la inclusión y la especialización en lengua y cultura cabécares en el territorio indígena de Ujarrás, muchas de estas problemáticas aún persisten; y en algunos casos se han agravado, según lo evidencia el hecho de que niños, niñas y jóvenes cabécares se sienten cada vez menos arraigados y menos identificados con su cultura, con los patrones de vida y las formas de organización comunitaria.

Con la escuela actual, con la enseñanza que reciben los y las escolares en III y IV ciclos, y con el servicio de Telesecundaria y Bachillerato instalados en el año 2000, todos servicios en español, puede aseverarse que la niñez y la adolescencia cabécares de Ujarrás están cada vez más desprovistos de valores, de una identidad indígena vigorosa y bien constituida, y de una autoestima alta. Incluso, muchos niegan, han perdido o desconocen su lengua autóctona.

Hasta este momento, tampoco la educación ha proveído a los cabécares de herramientas e instrumentos reales que les permitan insertarse en la vida comunal de modo positivo y productivo. 
Además del desgaste erosivo de su cultura, carecen de habilidades para la vida y el trabajo; aún así, continúan sobreviviendo y reproduciéndose, con una serie de vacíos que la educación no les ayuda a llenar.

A modo de conclusión, se vuelve necesario enfatizar que es de suma importancia tomar la decisión de implementar los cursos de lengua y cultura cabécares en Ujarrás, como puerta de entrada para revertir el efecto de los procesos de erosión y transculturación sufridos, históricamente, por estas comunidades.

Pero no sólo eso es suficiente, sino que se deben adecuar y fortalecer efectivamente estos programas, pues en el sistema educativo nacional hacen falta planteamientos y lineamientos claros, bien definidos, fundamentados en las pretensiones, las intenciones y los objetivos específicos que se persiguen, y que, además, estén sustentados en una visión estratégica que fortalezca y difunda la cultura y la lengua cabécares. Estos planteamientos y acciones, de ejecución obligatoria, deben ser consecuentes con la acción educativa cotidiana, e ir acordes con la aplicación, el desarrollo y la consolidación de los elementos curriculares vinculados a las estrategias.

\section{REFERENCIAS}

Constenla, A. (1994). Estado de situación de las lenguas indígenas de Costa Rica. Ponencia presentada en el Seminario en la Universidad de Costa Rica, San José, Costa Rica.

Costa Rica. Ministerio de Educación Pública [MEP]. Departamento de Educación Indígena [DEI]. (1995). Diagnósticos socioculturales indígenas. Estados de situación. San José, Costa Rica: CENADI-DEI-MEP.

Santa Cruz, M., y van der Lat, C. (2007). Estado de la situación educativa de la niñez y adolescencia indígenas de Costa Rica. San José: UNICEF. 